\title{
Correction to: MicroRNA-351 Promotes the Proliferation and Invasion of Glioma Cells through Downregulation of NAIF1
}

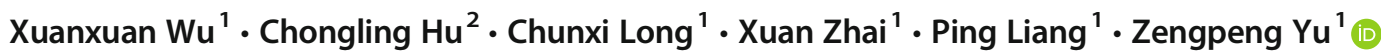

Published online: 14 July 2020

(C) Springer Science+Business Media, LLC, part of Springer Nature 2020

\section{Correction to: Journal of Molecular Neuroscience} https://doi.org/10.1007/s12031-020-01582-z

The original version of this article unfortunately contained mistakes in the Affiliation section, as below:

1. Affiliation 1 should be updated to: "Department of Neurosurgery, Children's Hospital of Chongqing Medical University, Chongqing Key Laboratory of Pediatrics, No. 136 Zhongshan 2nd Road, Yuzhong, Chongqing 400014, China".

2. Affiliation 2 should be removed as it is a redundant to Affiliation 3.

The updated affiliations are presented below.

Publisher's Note Springer Nature remains neutral with regard to jurisdictional claims in published maps and institutional affiliations.

The online version of the original article can be found at https://doi.org/ 10.1007/s12031-020-01582-Z

Chongling $\mathrm{Hu}$

1zhhcl@163.com

$\triangle$ Zengpeng Yu

Zengpeng.Yu85@gmail.com

1 Department of Neurosurgery, Children's Hospital of Chongqing Medical University, Chongqing Key Laboratory of Pediatrics, No. 136 Zhongshan 2nd Road, Yuzhong, Chongqing 400014, China

2 Department of Neural Tumor, Chongqing Key Laboratory of Translational Research for Cancer Metastasis and Individualized Treatment, Chongqing University Cancer Hospital, No. 181 Hanyu Road, Chongqing 400030, China 